\title{
Reflets du Siècle d'Or espagnol. Modèles en marge, sous la direction d'Anne Teulade
}

\section{Daniela Dalla Valle}

\section{(2) OpenEdition}

1 Journals

\section{Edizione digitale}

URL: http://journals.openedition.org/studifrancesi/5928

DOI: 10.4000/studifrancesi.5928

ISSN: 2421-5856

\section{Editore}

Rosenberg \& Sellier

\section{Edizione cartacea}

Data di pubblicazione: 1 mai 2011

Paginazione: 162

ISSN: 0039-2944

\section{Notizia bibliografica digitale}

Daniela Dalla Valle, «Reflets du Siècle d'Or espagnol. Modèles en marge, sous la direction d'Anne

Teulade», Studi Francesi [Online], 163 (LV | I) | 2011, online dal 30 novembre 2015, consultato il 08 janvier 2021. URL: http://journals.openedition.org/studifrancesi/5928 ; DOI: https://doi.org/10.4000/ studifrancesi.5928

Questo documento è stato generato automaticamente il 8 janvier 2021.

\section{(c)}

Studi Francesi è distribuita con Licenza Creative Commons Attribuzione - Non commerciale - Non opere derivate 4.0 Internazionale. 


\title{
Reflets du Siècle d'Or espagnol. Modèles en marge, sous la direction d'Anne Teulade
}

\author{
Daniela Dalla Valle
}

\section{NOTIZIA}

Reflets du Siècle d'Or espagnol. Modèles en marge, sous la direction d'Anne TEULADE, Nantes, Cécile Defaut, Université de Nantes, 2010, Collection «Horizons Comparatistes», pp. 274.

1 Questo volume comparatista, dedicato al Secolo d'Oro spagnolo e alla sua presenza in Europa fino al xx secolo, contiene alcuni studi riuniti da A. Teulade, che concernono specificamente i contatti tra Spagna e Francia all'interno del Seicento. Ricorderemo qui i cinque articoli secenteschi.

2 Didier SOUILLER (La réception du roman picaresque en France au XVII siècle, pp. 29-44), sottolinea la presenza di questo genere nella prima parte del Seicento, in cui esso è concepito come una storia "comique", soffermandosi in particolare sulla produzione di romanzi franco-spagnoli (scritti in spagnolo, ma pubblicati in Francia), sulle traduzioni in francese di romanzi picareschi, dal Lazarillo in poi, su alcuni testi teatrali collegabili al picaresco (soprattutto Scarron).

3 Catherine DUMAS ( La rénovation de la comédie par l'imitation de la "comedia": d'Ouville adaptateur de Calderón, pp.97-115) si sofferma ad analizzare tre opere di d'Ouville derivate da Calderón.

4 Monica PAVESIO (Voyages de textes de théâtre à travers l'Europe: le cas de l'“Astrólogo fingido" de Calderón, pp.117-141) si sofferma a sua volta su un'opera di Calderón, El astrólogo fingido, e analizza il complicato intersecarsi di imitazioni italiane, francesi, inglesi (compresa quella di d'Ouville). La studiosa è specialista della ripresa di Calderón in Francia (Alessandria, Edizioni dell'Orso, 2000), volume ormai fondamentale negli studi dedicati al successo del teatro calderoniano. 
5 Nicolas CORRERARD (La satire de la crédulité dans les imitations de "Don Quichotte" en France et en Angleterre, pp. 159-185) sposta l'attenzione su una delle opere essenziali del Secolo d'Oro, il Chisciotte, e per quanto riguarda la Francia ne studia l'imitazione libertina nel Gascon extravagant di Claireville.

6 Infine Véronique LOCHERT (Sur les marges des genres: l'hybridité du modèle espagnol au XVII siècle, pp. 225-238) concentra la sua attenzione sulla presenza di testi spagnoli nella letteratura francese del Seicento, in cui si manifesta-addirittura s'impone-la contaminazione fra generi diversi, soprattutto fra teatro e romanzo. 